\title{
Spatial differences in growth and sexual maturity between branches of a large population of the squat lobster Pleuroncodes monodon
}

\author{
Rubén Roa*, Fabián Tapia \\ Departamento de Oceanografía, Universidad de Concepción, Casilla 160-C, Concepción, Chile
}

\begin{abstract}
A large population of the squat lobster Pleuroncodes monodon inhabits the narrow continental shelf off central Chile. From a single nursery ground, 2 adult branches extend in a N-S orientation over $3^{\circ}$ of latitude, with the northern branch being much larger than the southern one. Squat lobsters from the southern branch are smaller on average than individuals from the northern branch. Two hypotheses were tested: (1) southern squat lobsters are smaller than northern ones because they grow to smaller sizes, and (2) southern squat lobsters are sexually mature at smaller sizes and earlier ages than northern squat lobsters. Using data from 6 research surveys done on the southern branch of the population, we estimated growth functions for male and female squat lobsters and compared them with previous results from the northern branch. Furthermore, using data from 1 survey we estimated a maturity function for southern females and compared it with a previous estimation for northern females. Southern squat lobsters grow faster and to smaller asymptotic sizes than northern ones, reaching sexuai maturity at smailer sizes and eariier ages. Moreover, individuais irom the southern branch. appear to live less ( 5 age classes) than individuals from the northern branch ( 8 to 9 age classes). These results imply that physiological processes are significantly faster in the southern branch. Previous cases of the same phenomenon in benthic crustaceans occurred in spatially discontinuous populations, while in this case it occurs between branches connected through a common nursery ground and separated by a relatively short distance. In this population, spatial heterogeneity in population functioning arises without physical discontinuities, but in the context of a branched population. Alternative hypotheses, based on features of the habitat, are posed to explain the difference. Finally, it was found that the ratio between size at $50 \%$ maturity and asymptotic size does not differ between branches, in agreement with the hypothesis that this ratio is a constant for a wide spectrum of phyla in the animal kingdom.
\end{abstract}

KEY WORDS: Population biology · Spatial heterogeneity Growth - Von Bertalanffy - Habitat features · Resampling statistics . Crustacean biology $\cdot$ Chile

\section{INTRODUCTION}

A large population of the squat lobster Pleuroncodes monodon (Decapoda: Galatheidae) extends along $3^{\circ}$ of latitude on the narrow continental shelf off central Chile. This population has a single nursery ground located at the shelf's southern tip (Fig. 1a), where recruits spend their first year of benthic life (Roa e: al. 1995). Two adult branches spread to the north and

\footnotetext{
·E-mail: rroa@udec.cl
}

south of the nursery ground, but the northern branch, which currently supports a commercial fleet of about 15 trawlers for half a year, is much larger than the southern one (Fig. 1a). Previous work has shown that the population is age structured, with an annual cycle of recruitment (Roa 1993, Gallardo et al. 1994). Unpublished observations from the commercial catch and research surveys in the 1980 s and 1990 s indicate that squat lobsters from the southern branch are smaller on average than individuals from the northern branch (Table 1). One possible explanation for this size difference is that southern squat lobsters experience higher mortality rates, hence older cohorts with the largest 


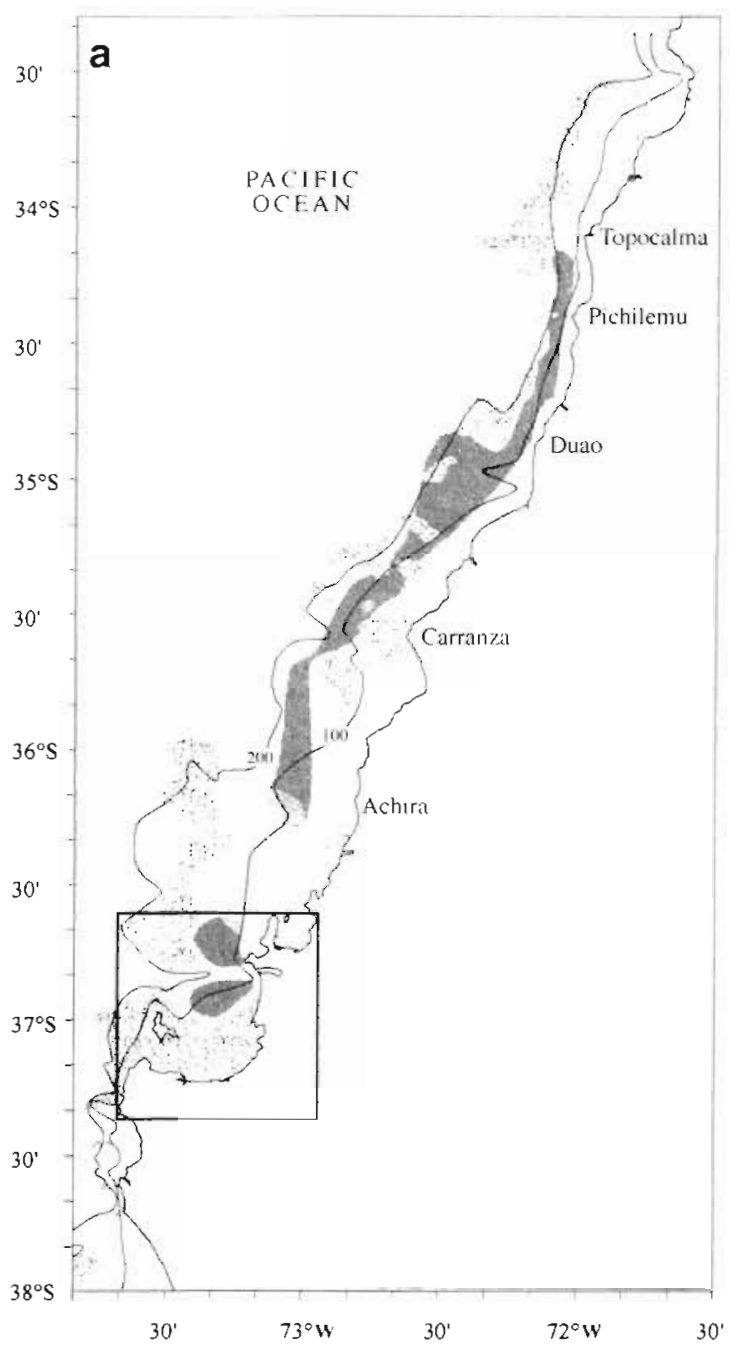

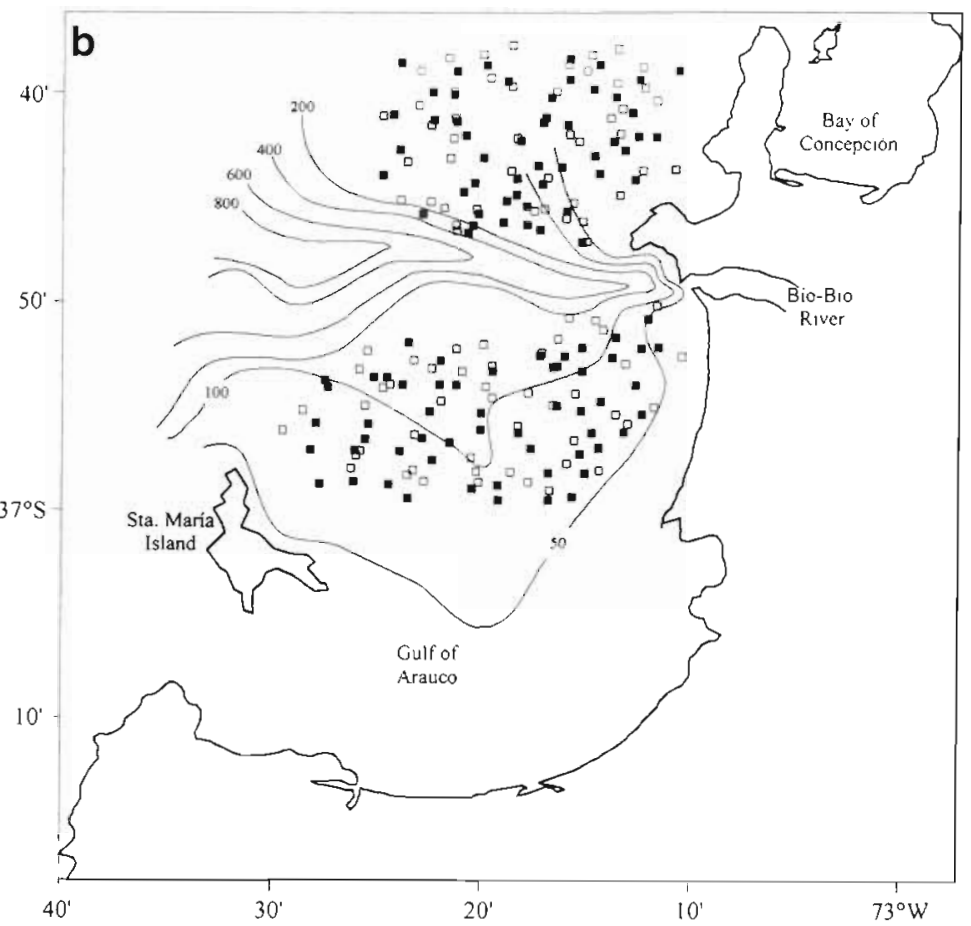

Fig. 1. (a) Spatial distribution of the squat lobster Pleuroncodes mon-

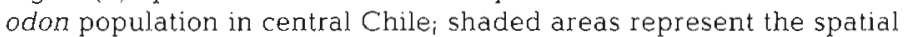
distribution of 2 adult population branches (dark grey) and of the nursery area (light grey), and irregularly dotted areas show hard, untrawlable bottoms. (b) Detail of the area enclosed in (a), showing stations visited in the southern branch during the 1995 (empty squares) and 1.996 (filled squares) research surveys individuals are not present. A second explanation, the one we pursue here, is that southern squat lobsters grow to smaller body sizes than northern ones. This proposed difference in growth between branches may be accompanied by different maturity schedules, as several studies on benthic crustaceans have shown (Campbell \& Eagles 1983, Somerton \& Otto 1986, Beyers \& Goosen 1987, Hines 1989, Bertness et al. 1991, Dugan et al. 1991). In these works less growth is associated with smaller sizes and earlier ages at maturity. Thus, we also test the hypothesis that the 2 population branches differ in size and age at maturity. Individual growth and sexual maturity are basic aspects of biomass production and population renewal, respectively; therefore, if differences exist in such processes, the branches would differ in a basic aspect of population functioning, despite the short distance between them and their sharing of a common nursery ground. In this work, we test the hypotheses posed above using
Table 1 Pleuroncodes monodon. Comparison of mean sizes between northern and southern branches of the squat lobster population. Note that mean sizes for both sexes are always larger in the northern branch. Source: Technical documents of the Undersecretariat of Fishing, Ministry of Economy, Valparaiso, Chile

\begin{tabular}{|c|c|c|c|c|}
\hline \multirow{2}{*}{ Year } & \multicolumn{2}{|c|}{ Males } & \multicolumn{2}{|c|}{ Females } \\
\hline & South & North & South & North \\
\hline 1982 & 27.4 & 28.4 & 25.2 & 26.2 \\
\hline 1983 & 27.9 & 30.2 & 25.5 & 27.4 \\
\hline 1984 & 27.1 & 32.1 & 25.3 & 27.2 \\
\hline 1986 & 31.1 & 33.3 & 28.4 & 28.6 \\
\hline 1989 & 29.0 & 31.5 & 27.6 & 29.0 \\
\hline 1991 & 27.8 & 32.0 & 26.5 & 32.0 \\
\hline 1992 & 33.5 & 35.1 & 31.0 & 32.6 \\
\hline 1993 & 34.4 & 36.5 & 31.6 & 34.3 \\
\hline
\end{tabular}


results from 6 research surveys done on the southern branch of the population between 1982 and 1996 and comparing them with previously published results for the northern branch (Roa 1993). We found that the expected differences do exist, but the causes remain to be understood.

\section{MATERIALS AND METHODS}

Sampling site. The southern branch of the squat lobster population inhabits the northern and southern sides of the Biobio River canyon (Fig. 1). Although this is the main topographic feature of the area, we do not report any comparison between squat lobsters from the southern and northern sides of the canyon, but treat them as a whole to be compared with what is known about squat lobsters to the north of the nursery ground (Roa 1993). Throughout the distribution range of squat lobsters, there are 2 types of benthic habitats: clean muddy bottoms (soft bottoms) and rocky-muddy bottoms (hard bottoms), which are characterised by the presence of abundant interspersed rocks lying on the sediment. Rocks are consolidated sediments of highly irregular shape and often heavily excavated (authors' pers. obs.), which may vary in diameter from a few centimetres to several meters. Because of the presence of these rocks, hard bottoms are not accessible for trawl sampling or fishing.

Data source. Length frequency data (LFD) were available from 4 research surveys done during March 1982, March 1983, Apri] 1984, and April 1986 on the southern branch of the squat lobster population. In those surveys, the LFD came from a random sample of the catch in each haul. Additionally, we obtained new LFD from 2 more surveys performed during spring 1995 (September 19 to October 22) and winter 1996 (July 15 to August 15) onboard the RV 'Kay-Kay' (Fig. 1b). In these latter surveys, the number of sampling stations visited in 1995 and 1996 was 116 and 107, respectively (Fig. 1b). Standard otter-trawl gear (25 $\mathrm{mm}$ mesh size) was used in all surveys.

At each station with squat lobster catch, a sample of ca 300 individuals was taken at random. Individuals were classified as males, females and ovigerous females, and their size was measured as carapace length ( $\mathrm{CL}$, i.e. ocular cavity to posterior tip of the cephalothorax) to the nearest $0.1 \mathrm{~mm}$. The same size measurement was done in the 4 surveys from the 1980s, with equal resolution. Non-ovigerous females were considered as sexually immature, although it is recognised that this criterion induced some error when large females, obviously sexually mature, did not carry eggs. However, histological analysis of gonad tissue for those large females was beyond the scope of this work.
Age structure and annual growth. Age structure and annual growth were analysed using the LFD set. We modelled growth as annual average increase in size, irrespective of how many moults were necessary to attain a given size increase. This approach allows using a continuous formulation as an approximation to crustacean discrete growth. LFD for males and females were analysed separately using unconstrained mixture distribution analysis (see Roa 1993 for details of our applications) implemented in the MIX algorithm (MacDonald \& Pitcher 1979). This analysis considers each LFD as the sampling realisation of a mixture of probability distributions. Parameter estimates of the distribution mixture are obtained by maximum likelihood. In our application the mixture is a collection of normally distributed year classes. Previous evidence supports this approach: in 1991-1992, recruitment in the nursery ground was found to have a single peak during the southern hemisphere autumn (Gallardo et al. 1994), and in 1993 the recruiting year class showed a normal size distribution (Roa et al. 1995). The estimated parameters are the mean, standard deviation, and proportional representation for each year class in each LFD.

Year classes from the 6 years of data were classified into relative age classes using the multiple-sample method of Roa \& Ernst (1996). A.bsolute age values were assigned according to the following criteria: the integer part of the assigned ages was obtained from the known size of the megalopae $\left(\mathrm{CL}_{t=0} \approx 5 \mathrm{~mm}\right)$, which provided a benchmark for the age of the youngest year classes and all the others, and the fractional part was obtained by dividing the number of months between the date of birth (Aprili Gallardo et al. 1994) and the month of the cruise by 12 . A von Bertalanffy growth model,

$$
C L(t)=C L_{\infty}\left\{1-\exp \left[-k\left(t-t_{0}\right)\right]\right\}
$$

where $C L_{\infty}$ is asymptotic carapace length, $k$ is a time rate constant, $t_{0}$ is age at zero size, and $t$ is age, was fitted by least-squares nonlinear regression using results of the age classification. In Roa (1993) and Roa \& Ernst (1996) the mean sizes of year classes were regressed against their assigned ages. This simple procedure gave all year classes equal weight even though some young and old year classes were less represented than intermediate-age year classes. In addition, the variance associated with the mean size of each normal year class was not taken into account. Hence, to improve the estimation of the growth models we implemented a Monte Carlo resampling algorithm (Crowley 1992, Manly 1997) in which each year class was resampled using a normal distribution with mean and variance estimated from MIX. For this task, and for all resampling work included in this work, we used FORTRAN for PowerStation (Anonymous 1995). The 
resulting quantiles were incremented according to the proportion estimated by MIX and sample size of each mixture. These resampled size values were assigned to a fixed age determined through the procedure indicated above. In this final output of age structure analysis the original sample of size data is associated with a vector of age estimates. However, we did not use the whole sample in fitting the growth model, since exploratory analysis showed that asymptotic stability is reached at about $1 / 10$ of the whole sample. Von Bertalanffy growth parameters were estimated by nonlinear least-squares regression from these resampled size-atage data using the NONLIN module of SYSTAT (Wilkinson 1988). The resampling procedure was also applied to the data from Roa (1993) for squat lobsters from the northern branch. The analysis of residual sum of squares (ARSS) modified for nonlinear least-squares regression (Chen et al. 1992) was used for comparing the fitted growth functions for males and females between both branches, and between sexes for both branches.

To compare growth rates of males and females of the northern and southern branches we used the first derivative of the growth function in Eq. (1), but expressed as a function of size instead of age:

$$
\frac{\mathrm{d} C L}{\mathrm{~d} t}=k\left[C L_{\infty}-C L(t)\right]
$$

Given that this derivative is a function of size, a test of differences between branches would involve comparing the distribution of the rate of growth through the size range. Therefore, in order to simplify we used the mean growth rate through the size range as the test statistic, which is defined as

$$
\frac{1}{C L_{2}-C L_{1}} \int_{C L_{1}}^{C L_{2}} \frac{\mathrm{d} C L}{\mathrm{~d} t} \mathrm{~d} C L=k\left(C L_{\infty}-\frac{C L_{2}{ }^{2}-C L_{1}{ }^{2}}{2\left(C L_{2}-C L_{1}\right)}\right)
$$

where $C L_{1}$ and $C L_{2}$ are the lower and upper limits of the size range. $C L_{1}$ was $5 \mathrm{~mm}$ (size of megalopae) for males and females of the northern and southern branches, and $C L_{2}$ was the integer size immediately below the asymptotic size. Quantiles of the distribution of mean growth rate were obtained using Monte Carlo resampling of growth parameters $k$ and $C L_{\infty}$, taking into account their correlation. The hypothesis of no difference between growth rates of the southern and northern branches was tested by evaluating the overlap of resampled $100(1-\alpha) \%$ confidence intervals. These intervals were built using the bootstrap percentile method (Efron \& Tibshirani 1993).

Sexual maturity. A logistic function,

$$
P(C L)=\frac{1}{1+\exp \left(\beta_{0}+\beta_{1} C L\right)}
$$

where $P$ is proportion of mature individuals and $\beta_{0}$ and $\beta_{1}$ are parameters, was fitted to data on maturity status at size using maximum-likelihood logistic regression (Hosmer \& Lemeshow 1989) in the NONLIN module of SYSTAT Our analysis considered that errors had a binomial probability distribution (Hosmer \& Lemeshow 1989). Data from 1996 was used for this analysis. Parameter estimates from the fitted maturity function were used to obtain the median size and median age at $50 \%$ sexual maturity $\left(C L_{50 \%}\right.$ and $t_{50 \%}$, respectively) and their asymptotic $95 \%$ confidence interval using a Monte Carlo algorithm called MATSIM (R. Roa, B. Ernst \& F. Tapia unpubl.). This algorithm performs a resampling of correlated maturity parameters of the logistic model and growth parameters of the von Bertalanffy model to generate an empirical probability distribution for $C L_{50 \%}$ and $t_{50 \%}$. The age at $50 \%$ maturity was obtained from

$$
t_{50 \%}=t_{0}-\frac{1}{k} \ln \left(1-\frac{C L_{50 \%}}{C L_{\infty}}\right)
$$

which is von Bertalanffy's growth model solved for $t$. In this application, the $t_{0}$ parameter was fixed. Differences in size and age at maturity between southern and northern female squat lobsters were assessed by evaluating the overlap of bootstrap-percentile confidence intervals.

A test of simultaneous changes in growth and maturity for females of the northern and southern branches can be performed using the adimensional statistic $C L_{50 \%} / C L_{\infty}$. For this task we collected $C L_{50 \%}$ quantiles from the output of the MATSIM algorithm. $C L_{\infty}$ quantiles were collected from a normal distribution defined by the estimate and its standard error obtained in the estimation of growth curves. As the numerator and denominator came from different estimation procedures, they were considered independent, so their ratio may be computed by random pairing of values for the numerator and denominator. Differences were tested by evaluating overlaps of bootstrap-percentile confidence intervals from northern and southern squat lobsters.

\section{RESULTS}

\section{Age structure and annual growth}

Results of the MIX distribution analysis are shown in Fig. 2 and Table 2. Four year classes were found for both sexes in each annual mixture between 1982 and 1986 (Fig. 2). Our data from the 1995 and 1996 surveys yielded a different age structure, consisting of 5 year classes, mainly due to the presence of recently recruited lobsters of less than $10 \mathrm{~mm}$ (Fig. 2). These 

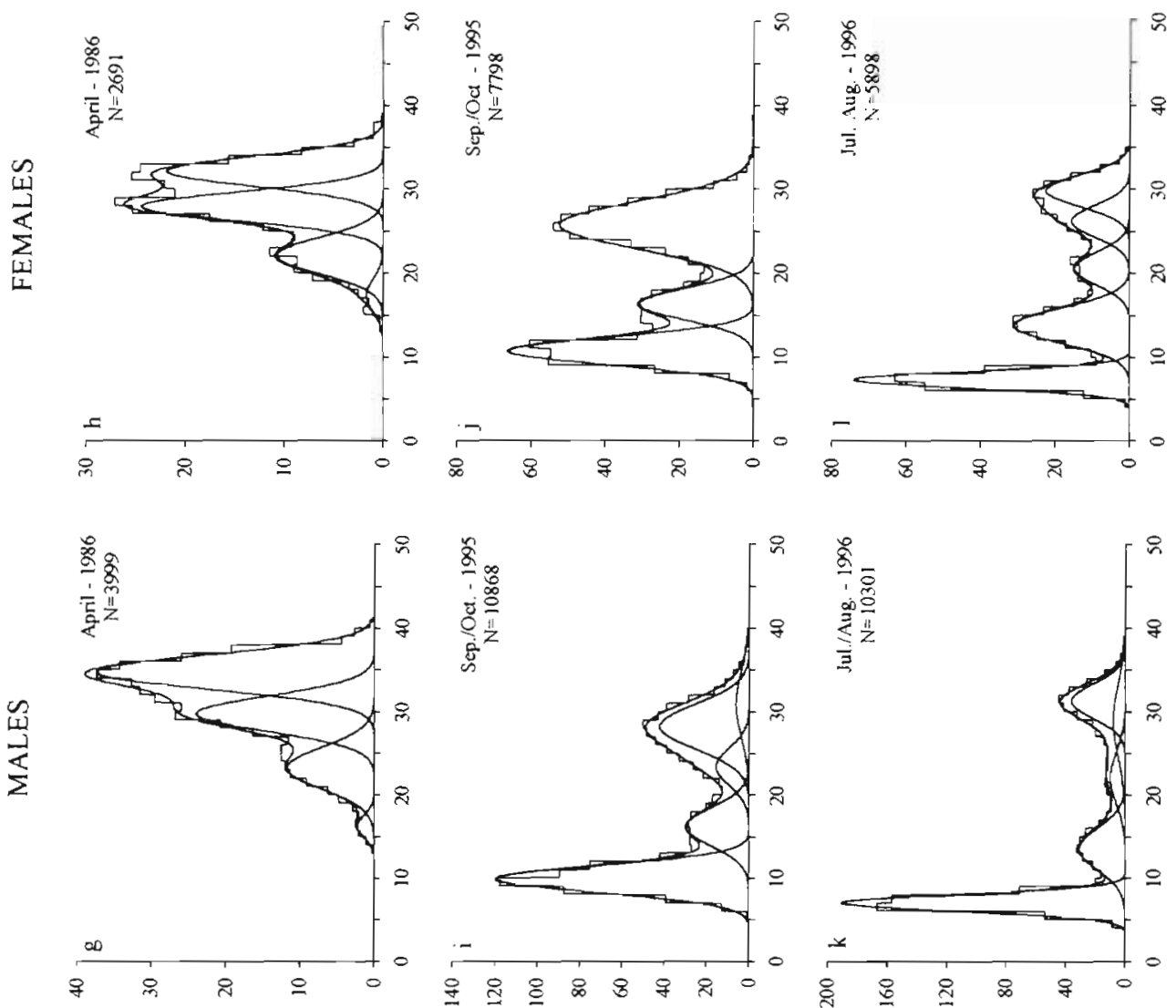

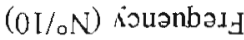
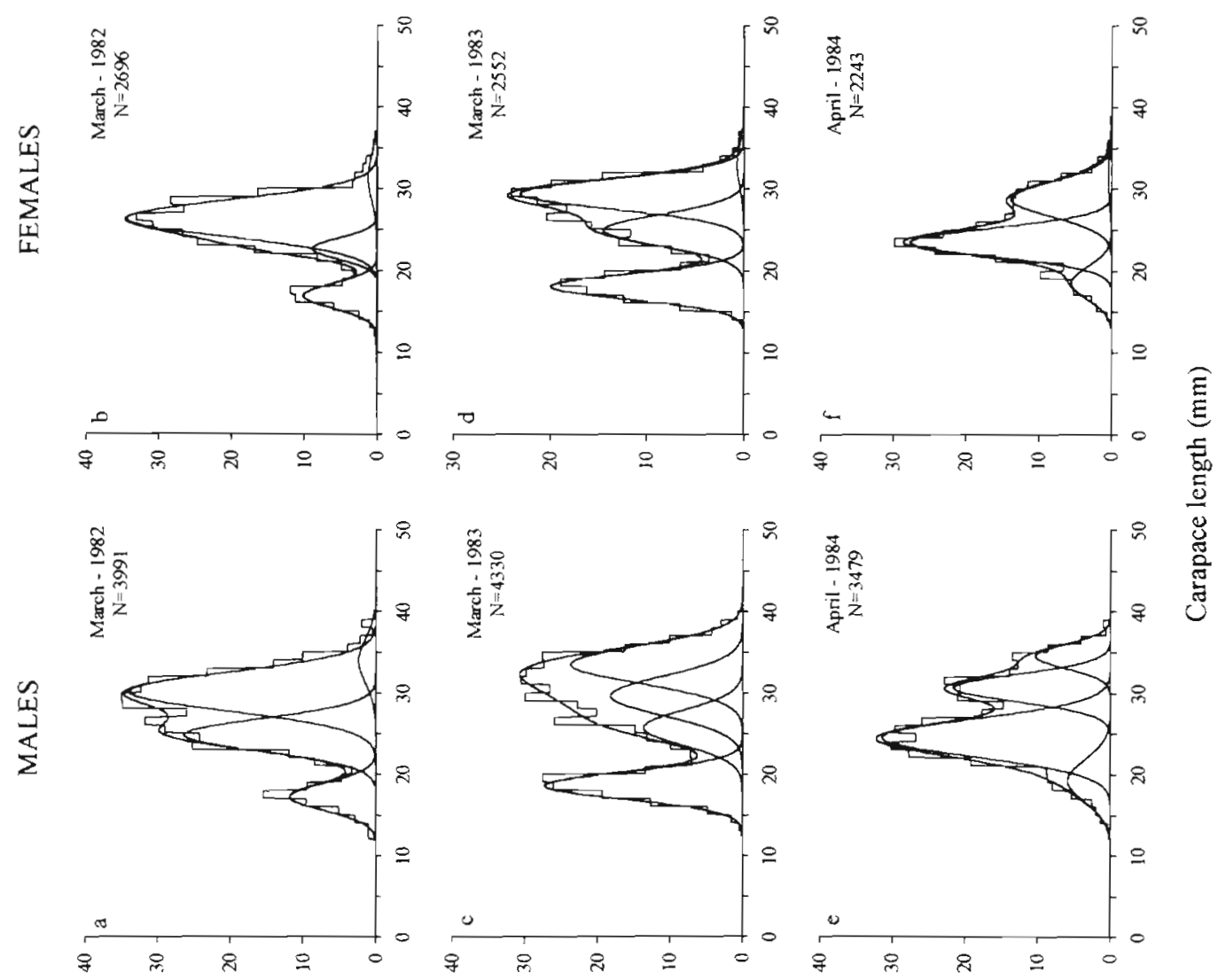

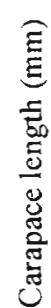

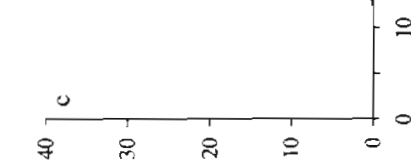

$(0 \%$ N) Kouənbad- 
Table 2. Pleuroncodes monodon. Results from the MIX analysis of length frequency distributions of squat lobsters from the southern branch. SD: standard deviation; $P$ : proportional representation of year classes in the distribution mixture. Standard errors in parentheses

\begin{tabular}{|c|c|c|c|c|c|c|c|c|}
\hline \multirow{2}{*}{$\begin{array}{l}\text { Sampling } \\
\text { year }\end{array}$} & \multirow[b]{2}{*}{ Year class } & \multirow{2}{*}{ Mean (mm) } & \multirow[b]{2}{*}{$\mathrm{SD}(\mathrm{mm})$} & \multirow[b]{2}{*}{$p$} & \multirow[b]{2}{*}{ Year class } & \multirow{2}{*}{$\begin{array}{l}\text { Femal } \\
\text { Mean (mm) }\end{array}$} & \multirow[b]{2}{*}{$\mathrm{SD}(\mathrm{mm})$} & \multirow[b]{2}{*}{$P$} \\
\hline & & & & & & & & \\
\hline \multirow[t]{4}{*}{1982} & 1 & $\begin{array}{l}17.246 \\
(0.097)\end{array}$ & $\begin{array}{c}1.694 \\
(0.075)\end{array}$ & 0.126 & 1 & $\begin{array}{l}16.879 \\
(0.098)\end{array}$ & $\begin{array}{c}1.519 \\
(0.077)\end{array}$ & 0.144 \\
\hline & 2 & $\begin{array}{l}24.839 \\
(0.084)\end{array}$ & $\begin{array}{c}1.982 \\
(0.078)\end{array}$ & 0.328 & 2 & $\begin{array}{l}22.648 \\
(0.177)\end{array}$ & $\begin{array}{c}1.289 \\
(0.158)\end{array}$ & 0.107 \\
\hline & 3 & $\begin{array}{c}30.142 \\
(0.086)\end{array}$ & $\begin{array}{l}2.356 \\
10.093)\end{array}$ & 0.503 & 3 & $\begin{array}{c}26.340 \\
(0.065)\end{array}$ & $\begin{array}{c}2.224 \\
(0.068)\end{array}$ & 0.714 \\
\hline & 4 & $\begin{array}{c}33.930 \\
(0.793)\end{array}$ & $\begin{array}{c}2.836 \\
(0.568)\end{array}$ & 0.043 & 4 & $\begin{array}{l}31.371 \\
(0.623)\end{array}$ & $\begin{array}{c}2.830 \\
(0.510)\end{array}$ & 0.035 \\
\hline \multirow[t]{4}{*}{1983} & 1 & $\begin{array}{l}18.600 \\
(0.066)\end{array}$ & $\begin{array}{c}1.648 \\
(0.049)\end{array}$ & 0.261 & 1 & $\begin{array}{l}18.041 \\
(0.069)\end{array}$ & $\begin{array}{c}1.531 \\
(0.053)\end{array}$ & 0.300 \\
\hline & 2 & $\begin{array}{l}25.719 \\
(0.251)\end{array}$ & $\begin{array}{c}2.152 \\
(0.272)\end{array}$ & 0.170 & 2 & $\begin{array}{c}24.944 \\
(0.119)\end{array}$ & $\begin{array}{c}1.897 \\
(0.114)\end{array}$ & 0.270 \\
\hline & 3 & $\begin{array}{l}29.634 \\
(0.186)\end{array}$ & $\begin{array}{c}2.413 \\
(0.383)\end{array}$ & 0.254 & 3 & $\begin{array}{l}29.371 \\
(0.083)\end{array}$ & $\begin{array}{l}1.807 \\
(0.083)\end{array}$ & 0.411 \\
\hline & 4 & $\begin{array}{l}33.490 \\
(0.177)\end{array}$ & $\begin{array}{c}2.297 \\
(0.117)\end{array}$ & 0.315 & 4 & $\begin{array}{l}32.875 \\
(1.126)\end{array}$ & $\begin{array}{c}2.622 \\
(1.038)\end{array}$ & 0.018 \\
\hline \multirow[t]{4}{*}{1984} & 1 & $\begin{array}{l}19.297 \\
(0.234)\end{array}$ & $\begin{array}{c}2.604 \\
(0.175)\end{array}$ & 0.111 & 1 & $\begin{array}{l}18.575 \\
(0.195)\end{array}$ & $\begin{array}{c}2.009 \\
(0.136)\end{array}$ & 0.125 \\
\hline & 2 & $\begin{array}{l}24.526 \\
(0.082)\end{array}$ & $\begin{array}{c}2.298 \\
(0.075)\end{array}$ & 0.520 & 2 & $\begin{array}{l}23.529 \\
(0.074)\end{array}$ & $\begin{array}{c}1.702 \\
(0.061)\end{array}$ & 0.527 \\
\hline & 3 & $\begin{array}{l}30.673 \\
(0.102)\end{array}$ & $\begin{array}{c}1.667 \\
(0.081 .)\end{array}$ & 0.259 & 3 & $\begin{array}{l}28.811 \\
(0.136)\end{array}$ & $\begin{array}{c}2.122 \\
(0.108)\end{array}$ & 0.329 \\
\hline & 4 & $\begin{array}{l}34.564 \\
(0.122)\end{array}$ & $\begin{array}{c}1.469 \\
(0.090)\end{array}$ & 0.110 & 4 & $\begin{array}{l}31.692 \\
(1.839)\end{array}$ & $\begin{array}{c}3.608 \\
(1.379)\end{array}$ & 0.020 \\
\hline \multirow[t]{4}{*}{1986} & 1. & $\begin{array}{c}16.263 \\
(0.236)\end{array}$ & $\begin{array}{c}1.361 \\
(0.180)\end{array}$ & 0.019 & 1 & $\begin{array}{l}17.377 \\
(0.412)\end{array}$ & $\begin{array}{c}1.957 \\
(0.319)\end{array}$ & 0.031 \\
\hline & 2 & $\begin{array}{l}23.238 \\
(0.152)\end{array}$ & $\begin{array}{c}2.492 \\
(0.120)\end{array}$ & 0.185 & 2 & $\begin{array}{l}22.099 \\
(0.154)\end{array}$ & $\begin{array}{c}2.150 \\
(0.135)\end{array}$ & 0.216 \\
\hline & 3 & $\begin{array}{l}29.757 \\
(0.111)\end{array}$ & $\begin{array}{c}2.107 \\
(0.089)\end{array}$ & 0.317 & 3 & $\begin{array}{l}27.946 \\
(0.093)\end{array}$ & $\begin{array}{c}1.715 \\
(0.076)\end{array}$ & 0.390 \\
\hline & 4 & $\begin{array}{c}34.751 \\
(0.066)\end{array}$ & $\begin{array}{c}2.041 \\
(0.049)\end{array}$ & 0.479 & 4 & $\begin{array}{l}32.141 \\
(0.085)\end{array}$ & $\begin{array}{c}1.782 \\
(0.063)\end{array}$ & 0.363 \\
\hline \multirow[t]{5}{*}{1995} & 1 & $\begin{array}{c}9.890 \\
(0.029)\end{array}$ & $\begin{array}{c}1.604 \\
(0.022)\end{array}$ & 0.440 & 1 & $\begin{array}{l}10.727 \\
(0.040)\end{array}$ & $\begin{array}{c}1.603 \\
(0.030)\end{array}$ & 0.341 \\
\hline & 2 & $\begin{array}{l}16.205 \\
(0.117)\end{array}$ & $\begin{array}{l}2.303 \\
(0.081)\end{array}$ & 0.158 & 2 & $\begin{array}{l}16.323 \\
(0.082)\end{array}$ & $\begin{array}{l}1.867 \\
(0.067)\end{array}$ & 0.185 \\
\hline & 3 & $\begin{array}{l}23.441 \\
(0.220)\end{array}$ & $\begin{array}{c}2.279 \\
(0.223)\end{array}$ & 0.082 & 3 & $\begin{array}{l}25.756 \\
(0.054)\end{array}$ & $\begin{array}{c}2.817 \\
(0.42)\end{array}$ & 0.474 \\
\hline & 4 & $\begin{array}{c}28.248 \\
{[0.129]}\end{array}$ & $\begin{array}{c}2.694 \\
(0.111)\end{array}$ & 0.262 & & & & \\
\hline & 5 & $\begin{array}{l}30.968 \\
(0.710)\end{array}$ & $\begin{array}{c}3.974 \\
(0.444)\end{array}$ & 0.058 & & & & \\
\hline \multirow[t]{5}{*}{1996} & 1 & $\begin{array}{l}7.043 \\
(0.017)\end{array}$ & $\begin{array}{c}0.989 \\
(0.013)\end{array}$ & 0.458 & 1 & $\begin{array}{c}7.316 \\
(0.026)\end{array}$ & $\begin{array}{c}0.956 \\
(0.021)\end{array}$ & 0.301 \\
\hline & 2 & $\begin{array}{l}13.542 \\
(0.096)\end{array}$ & $\begin{array}{c}0.989 \\
(0.013)\end{array}$ & 0.191 & 2 & $\begin{array}{l}13.788 \\
(0.071)\end{array}$ & $\begin{array}{l}2.048 \\
(0.066)\end{array}$ & 0.271 \\
\hline & 3 & $\begin{array}{l}22.081 \\
(0.262)\end{array}$ & $\begin{array}{c}3.139 \\
(0.274)\end{array}$ & 0.078 & 3 & $\begin{array}{l}20.590 \\
(0.156)\end{array}$ & $\begin{array}{c}1.968 \\
(0.107)\end{array}$ & 0.124 \\
\hline & 4 & $\begin{array}{l}29.007 \\
(0.455)\end{array}$ & $\begin{array}{c}4.389 \\
(0.273)\end{array}$ & 0.090 & 4 & $\begin{array}{l}26.229 \\
(0.149)\end{array}$ & $\begin{array}{c}1.881 \\
(0.147)\end{array}$ & 0.126 \\
\hline & 5 & $\begin{array}{l}31.298 \\
(0.079)\end{array}$ & $\begin{array}{c}2.064 \\
(0.058)\end{array}$ & 0.183 & 5 & $\begin{array}{c}29.852 \\
(0.098)\end{array}$ & $\begin{array}{c}1.867 \\
(0.075)\end{array}$ & 0.178 \\
\hline
\end{tabular}

recently recruited year classes can be safely assigned an integer age of $0 \mathrm{yr}$, since their size difference to megalopae (about $5 \mathrm{~mm}$ ) can be attributed to growth between the period of settlement (southern hemisphere autumn; Gallardo et al. 1994) and the sampling periods (spring for 1995 and winter for 1996). In gen- 


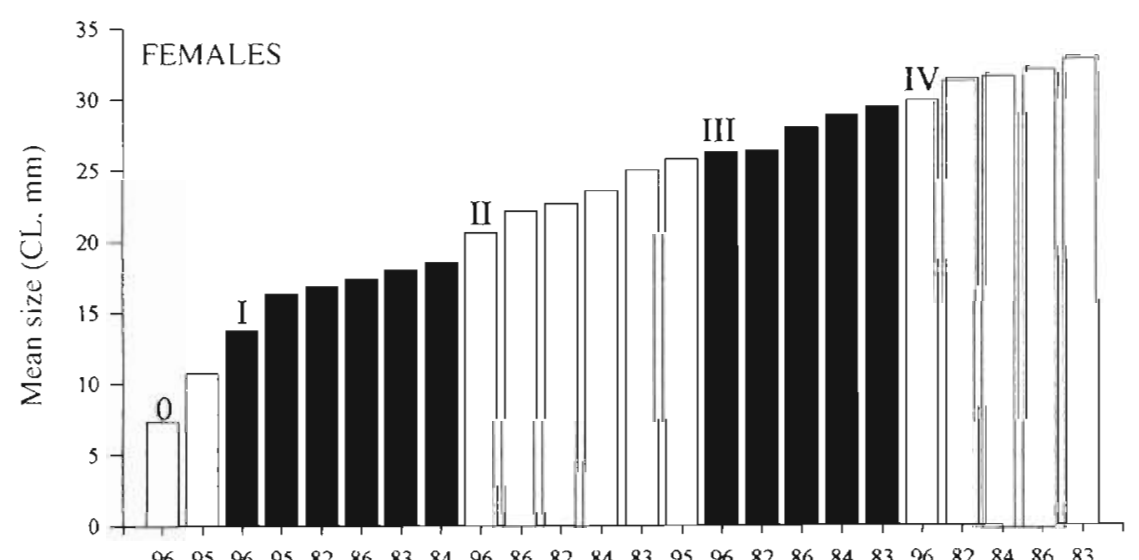

$\begin{array}{llllllllllllllllllllllll}96 & 95 & 96 & 95 & 82 & 86 & 83 & 84 & 96 & 86 & 82 & 84 & 83 & 95 & 96 & 82 & 86 & 84 & 83 & 96 & 82 & 84 & 86 & 83\end{array}$

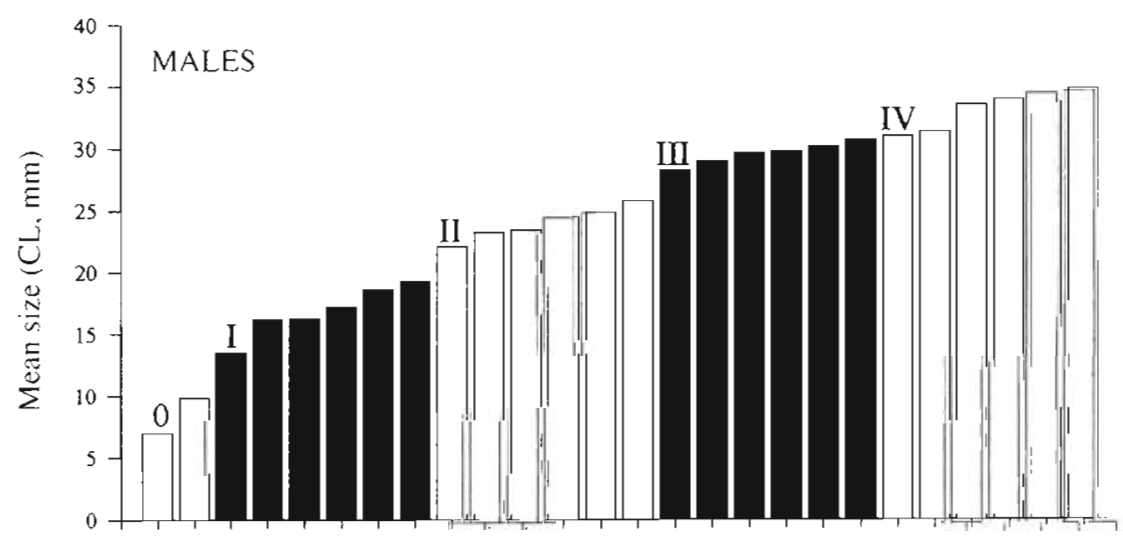

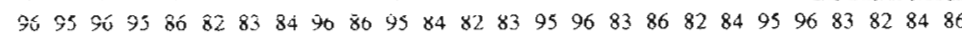

Fig. 3. Pleuroncodes monodon. Mean size of year classes identified by MIX for squat lobsters from the southern branch. The calendar year is shown on the abscissa. Adjacent age classes are shown by contrasting fill patterns and indicated by roman numerals

Year

eral, most year classes were well defined by MIX analysis (Table 2), in the sense that they showed a moderate standard deviation $(<3 \mathrm{~mm})$ and significant proportional representation $(>5 \%)$. However, 3 out of 26 year classes of males were badly defined, for they showed high standard deviations and low proportions (year classes 5 in 1995, 3 in 1996, and 4 in 1996; Table 2). In females there was only 1 poorly defined year class (year class 4 in 1984; in Table 2). These 4 year classes appear as flattened and poorly represented distributions in Fig. $2 \mathrm{~d}$, $\mathrm{i}$ and $\mathrm{k}$ and they were weighted down by the resampling procedure in the posterior estimation of the growth model.

Application of the multiple-sample procedure of Roa \& Ernst (1996) gave a total of 5 annual age classes for both males and females (Fig. 3). Least-squares regression for the growth functions of males and females from the southern branch yielded residuals with an appropriate behaviour, that is evenly and randomly distributed along the range of the predictor variable (Fig. 4). Growth models fitted for males and females of the southern branch (Fig. 4) were significantly different according to the Chen et al. (1992) $F$-test ( $F=78.59$; $\mathrm{df}=3,6081 ; \mathrm{p} \ll 0.001)$. At the same time, significant differences were found when comparing growth curves between northern and southern branches for males $(F=1160.4 ; \mathrm{df}=2,6741 ; \mathrm{p} \ll 0.001)$ and females $(F=2344.5 ; \mathrm{df}=2,4381 ; \mathrm{p} \ll 0.001)$. It is clear from these results that lobsters from the southern branch grow to significantly smaller sizes than lobsters from the northern branch. Despite this, mean growth rates were significantly higher in southern than in northern lobsters for both sexes (Table 3 ).

\section{Sexual maturity}

In one way, residuals of the fitted maturity model behaved as expected for a binomial error distribution: variance was maximum at intermediate values of the predictor variable (Fig. 5). However, in another way, residuals departed from assumptions: there was a nonrandom pattern of the mean residual distribution along the predictor variable (Fig. 5). Inspection of Fig. 5 shows that the true maturity curve seems to be steeper than the estimated one, but was smoothed by large- 

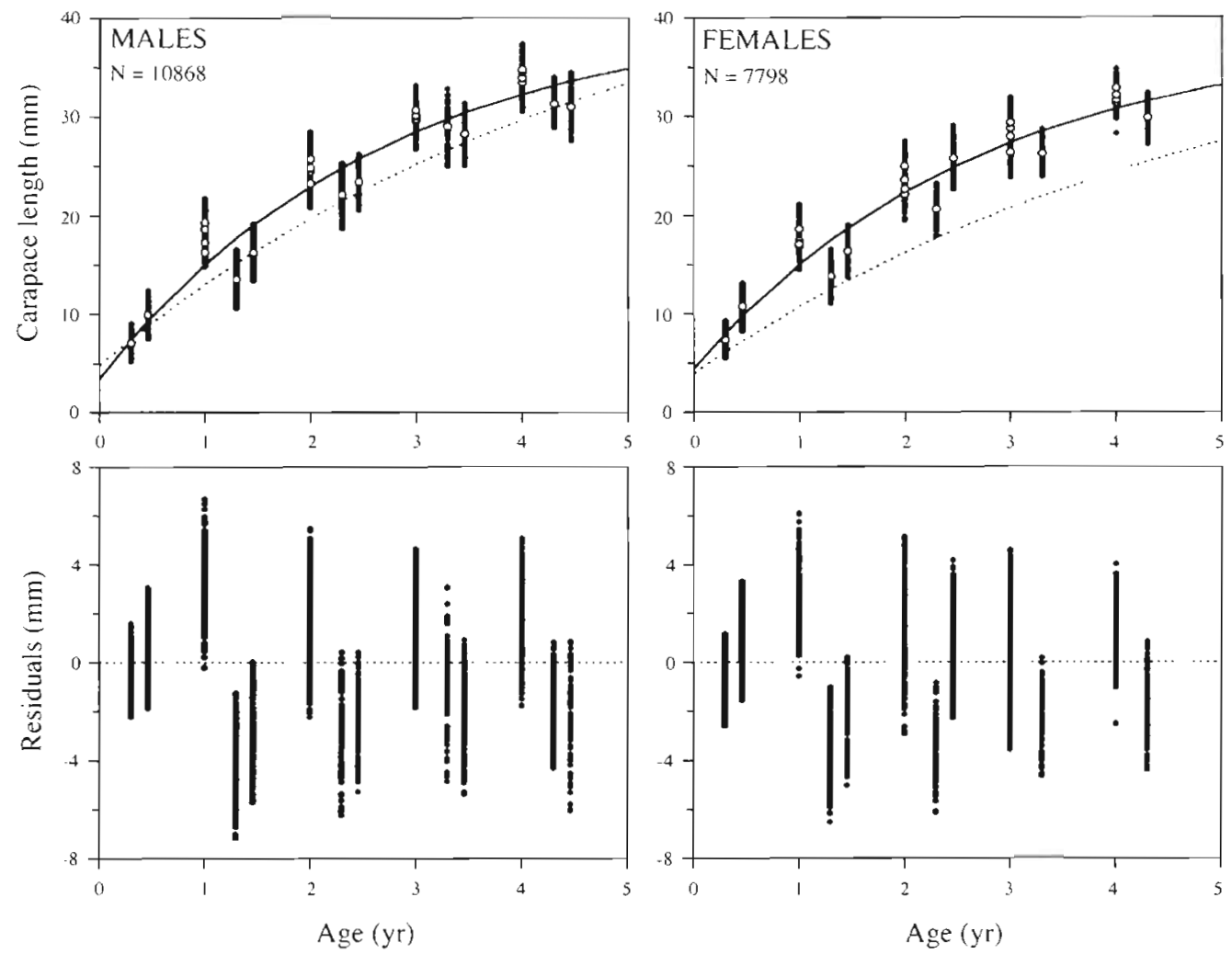

Fig. 4. Pleuroncodes monodon. Von Bertalanffy growth functions in male and female squat lobsters from the southern branch. Open circles: mean size at age; filled circles: resampled data on individual size at age; dotted lines: growth functions fitted for squat lobsters from the northern branch (from Roa 1993). Residuals are shown in the bottom panels

Table 3. Pleuroncodes monodon. Estimates of growth and maturity parameters for squat lobsters from the southern and northern branch. Estimates of maturity parameters in the north were taken from Roa (1993). Standard errors in parentheses. $C L_{\text {so: }}$ asymptotic carapace length; $k$ : time rate constant; $t_{0}$ : age at zero size $\beta_{0}$ and $\beta_{1}$ : maturity parameters; $C L_{50 \%}$ : carapace length at $50 \%$ sexual maturity; $t_{50 \%}$ : age at $50 \%$ sexual maturity

\begin{tabular}{|c|c|c|c|c|}
\hline \multirow[b]{2}{*}{ Parameter } & \multicolumn{2}{|c|}{ Southern branch } & \multicolumn{2}{|c|}{ Northern branch } \\
\hline & Males & Females & Males & Females \\
\hline \multicolumn{5}{|c|}{ Growth in length (Eq. 1) } \\
\hline$C L_{s o}(\mathrm{~mm})$ & $40.783(0.418)$ & $38.361(0.562)$ & $50.039(0.311)$ & $41.298(0.369)$ \\
\hline$k\left(y r^{-1}\right)$ & $0.371(0.009)$ & $0.375(0.012)$ & $0.200\{0.002\}$ & $0.199(0.003)$ \\
\hline$t_{0}(y r)$ & $-0.240(0.012)$ & $-0.328(0.019)$ & $-0.510($ fixed $)$ & -0.510 (fixed) \\
\hline$r^{2}$ & 0.990 & 0.990 & 0.998 & 0.996 \\
\hline \multicolumn{5}{|c|}{ Growth rate (Eq. 3) } \\
\hline Median & 6.600 & 6.075 & 4.437 & 3.534 \\
\hline $95 \% \mathrm{CI}$ & $5.403-6.924$ & $4.563-6.462$ & $3.060-4.652$ & $2.073-3.751$ \\
\hline \multicolumn{5}{|c|}{ Sexual maturity (Eq. 4) } \\
\hline$\beta_{0}$ & & $9237(1.414)$ & & $13.648(2.615)$ \\
\hline$\beta_{1}$ & & $-0.406(0.061)$ & & $-0.502(0.095)$ \\
\hline$C L_{50 \%}$ & & 22.74 & & 27.19 \\
\hline $95 \% \mathrm{CI}$ & & $21.30-24.16$ & & $25.86-28.51$ \\
\hline$t_{50 \%}$ & & 2.07 & & 4.89 \\
\hline $95 \% \mathrm{CI}$ & & $1.84-2.33$ & & $4.44-5.38$ \\
\hline \multicolumn{5}{|c|}{$C L_{50 \%} / C L_{s}$ ratio } \\
\hline Median & & 0.625 & & 0.658 \\
\hline $95 \% \mathrm{CI}$ & & $0.553-0.712$ & & $0.592-0.720$ \\
\hline
\end{tabular}



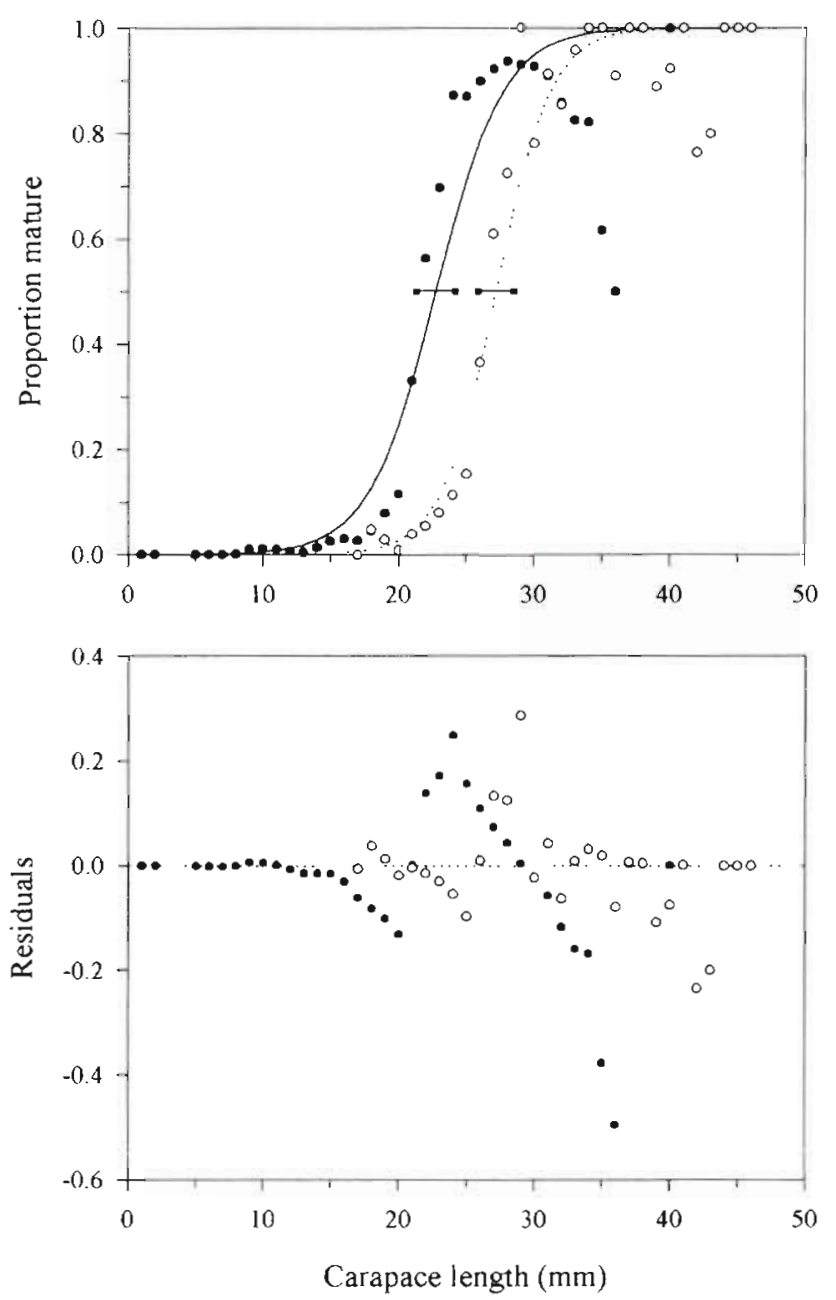

Fig. 5. Pleuroncodes monodon. Maturity data (filled circles) and function (solid line) fitted for female squat lobsters from the southern branch. Open circles and dotted line are maturity data and fitted function for northern lobsters (from Roa 1993). Horizontal lines: $95 \%$ asymptotic confidence intervals for size at $50 \%$ sexual maturity $\left(C L_{50}\right.$. $)$. Residuals for both branches are shown in the bottom panel

sized females which showed no trace of eggs by the time of sampling (presumably due to early hatching of eggs). The data showing a decrease in the proportion of ovigerous females between 30 and $40 \mathrm{~mm}$ size make up $17 \%$ (1004 out of 5901 ) of the total sample and $47 \%$ (901 out of 1928) of females classified as mature. Therefore, our maturity parameter estimates from the logistic model are probably biased. The estimated median size at $50 \%$ sexual maturity $\left(C L_{50 \%}\right)$ for the southern branch was $22.74 \mathrm{~mm}$. The confidence intervals for median size at maturity of the southern and northern branches did not overlap (Fig. 5 and Table 3), indicating a significant difference. This is despite possible misestimation of maturity parameters in the southern branch, which could have obscured the dif- ference. Estimated ages at $50 \%$ sexual maturity $\left(t_{50 \%}\right)$ for both branches were also different, with a distance of about 3 yr between median estimates (Table 3). Northern and southern females did not differ in the $C L_{50 \%} / C L_{\infty}$ ratio (Table 3 ). Female squat lobsters from both branches reach sexual maturity at an average size between 55 and $72 \%$ of their asymptotic size.

\section{DISCUSSION}

Our results support the view that both branches of the large squat lobster population inhabiting the continental shelf off central Chile differ in 2 basic aspects of their functioning: southern squat lobsters grow faster and to smaller sizes than northern ones, and females mature earlier. Furthermore, squat lobsters from the southern branch appear to live less (5 age classes) than individuals from the northern branch (8 to 9 age classes; Roa 1993, Roa et al. 1995). These results imply that physiological processes are significantly faster in the southern branch. Previous cases of the same phenomenon in benthic crustaceans occurred in spatially discontinuous populations (e.g. Somerton 1981, Campbell \& Eagles 1983, Somerton \& Otto 1986, Beyers \& Goosen 1987. Hines 1989, Bertness et al. 1991, Dugan et al. 1991), while in this case it occurs between branches connected through a common nursery ground and separated by a relatively short distance (Fig. 1a). In this population, spatial heterogeneity in population functioning arises without physical discontinuities, but in the context of a branched population. This result highlights the importance of studying populations in their spatial dimension, not only because of habitat physiognomy (i.e. the spatial layout of different elements of the habitat; Dunning et al. 1992) but also because of population physiognomy. In our case, it is the presence of a nursery ground located between regions of suitable habitats for adults which causes branching and then the potential for different functioning between branches. The remaining question is, why do these 2 branches show such a contrasting functioning?

We may look for causative factors in the individuals composing the 2 branches and/or in the habitats they live in. In the first case, individuals might be genetically heterogeneous, and then the squat lobster large population would be composed of 2 different populations. However, genetic differences are unlikely because both branches share a common source of recruits (Roa et al. 1995). In addition, preliminary genetic analyses in which 181 individuals from the southern branch, nursery ground and northern branch were compared at 2 polymorphic loci indicated no difference between them (authors' unpubl. results). 
Hence, we favour the hypothesis that spatial variation in growth and maturity should result from phenotypic responses to habitat conditions faced during benthic life. At this point, several alternative explanations may be explored. First, Bertness et al. (1991) and Beyers \& Goosen (1987, and references therein) identified food supply as the main factor behind differences in growth and maturity in the acorn barnacle Semibalanus baIanoides and the rock lobster Jasus lalandii, respectively. Squat lobsters feed mainly on detritus, although they can also consume polychaetes and amphipods (Gallardo 1980, and authors' unpubl. results). Thus organic matter content of the sediments may be a reliable measure of food supply to the squat lobsters. Samples taken on the southern ( $\mathrm{n}=102$; authors' unpubl results) and northern ( $\mathrm{n}=46$; Gallardo 1980) branches show that organic matter content is high $(>10 \%$ dry weight) in both areas, although the sample from the northern branch covered only a small part of it. However, similar food concentrations do not imply similar diet compositions in both branches, and this could be the reason for the observed differences in growth and maturity in squat lobsters.

Second, hydrographic conditions and especially water temperature may also influence growth and maturity in benthic crustaceans through its effect on metabolic rates (Campbell \& Eagles 1983, Somerton \& Otto 1986, Hines 1989, Dugan et al. 1991). In Wenner et al.'s (1985) review of variation in size at onset of maturity in crustaceans, faster growth and earlier maturity were associated with higher temperature regimes in laboratory populations of copepods. In our case, both population branches are covered by either of 2 water masses, depending on the intensity of upwelling: the surface equatorward sub-Antarctic water and the subsurface poleward Equatorial water (Fonseca 1989). Both water masses are relatively cold $\left(<12^{\circ} \mathrm{C}\right)$ but differ in salinity and oxygen content (Gallardo et al. 1996, and references therein). On a large spatial scale, there seem to be no major differences in bottom hydrographic conditions between the northern and southern branches (Bahamonde et al. 1986, Anonymous 1996). Nonetheless, little is known about the detailed oceanographic dynamics along the continental shelf off central Chile. The southern branch inhabits a much more intricate topography than the northern one, with 2 embayments and the Biobio River canyon as its main topographic features. These habitat features may generate circulation patterns contributing to a local change in near-bottom oceanographic conditions at the southern branch. An additional feature of the southern branch is the significant discharge of freshwater and sedimentary material carried by the Biobio River into the Gulf of Arauco (Fig. 1), the effect of which on habitat conditions for squat lobsters remains to be investigated. Moreover, the existence of seasonal fluctuations in bottom water temperatures over the whole population may produce differences in growth rates by affecting recruits that have settled at different times during the breeding season. Having this in mind, Wenner et al. (1985) indicated that cohorts recruiting earlier during the breeding season may experience more favourable conditions of temperature, leading to faster growth rate and younger age of maturity in early recruits. This could be the case for squat lobsters if there were an asynchronic larval release. and a consequent time lag in recruitment between branches. The maturity curves shown in Fig. 5 for the 2 branches are quite similar in shape despite a 3 mo difference between them (November 1991 and August 1996 for north and south, respectively). Although these curves were constructed from data gathered in different years, unpublished results from a stock assessment carried out over the entire population in November 1996 show the same shape for the northern branch and almost no egg-bearing females in the south. Therefore, an asynchronic larval release seems to occur along the population, although a hypothetical difference in the timing and/or location of recruitment for the 2 branches cannot be confirmed at the moment

Third, predation pressure may also explain the observed differences between branches. One of the most clear examples of such an effect was provided by Reznick et al. (1997) for the freshwater fish Poecilia reticulata: fishes in ponds with high predation pressure live less, grow to smaller sizes and mature earlier than fishes in ponds with low predation pressure, although in those populations physiological differences are genetically based. In the case of the squat lobster, the main predation pressure comes from demersal fishes (Arancibia \& Meléndez 1987). Unfortunately, we lack studies on local variations in predation pressure that could shed light on their possible role in the differences in growth and maturity found between population branches

Fourth, inspection of Fig. 1a shows that the most striking feature of the habitat in the southern branch, as compared to the habitat in the northern branch, is that it is surrounded by emerged land (the southern tip of the Gulf of Arauco) and a large submerged region of hard bottoms. Farther south, soft and trawlable bottoms arise again (Fig. 1a), but squat lobsters catches have not been reported there despite decades of trawling for the hake Merluccius gayi (I. Payá, Fisheries Development Institute, pers. comm.). This absence of squat lobsters south of the Gulf of Arauco suggests that the southern branch is spatially confined and therefore cannot expand towards the south. This putative confinement of the southern branch allows postulating a further hypothesis to explain the different functioning 
between the 2 branches: individuals inhabiting a spatially confined habitat expend less energy in movement and consequently can accelerate their physiological rates, completing their life cycles in less time. At the present level of knowledge, however, it is not possible to identify with any level of certainty which of the proposed hypotheses best explain our main result.

It is interesting to note that males showed a greater difference in growth between southern and northern branches than females. However, it is also true that southern females mature at least 2 yr earlier than northern ones, and at a significantly smaller size. It could be that southern and northern female squat lobsters respond to their different habitats mainly through sexual maturity and secondarily through growth. This could be related to the energetic cost of carrying the eggs. Males however, without such an investment in reproductive tissue, could only be responding to the different habitats through adjustments of growth rate.

As a final point, it is interesting to note that despite differences in growth and maturity in females, the ratio of median size at maturity to asymptotic size $\left(C L_{50 \%} / C L_{\infty}\right)$ does not differ between the 2 branches. This result shows that the change in any one processgrowth or maturity - is accompanied by a proportional change in the other process, as it should be if growth and sexual maturity are closely linked at the physiological level (Calow \& Townsend 1981). In fact, several studies on benthic crustaceans have shown that spatial variation in maximum size is accompanied by a directly proportional variation in age and/or size at maturity (Campbell \& Eagles 1983, Somerton \& Otto 1986, Beyers \& Goosen 1987, Hines 1989, Bertness et al. 1991, Dugan et al. 1991). In addition, the work of Reznick et al. (1997) has clearly demonstrated the strong link between asymptotic size and size and age at maturity in Poecilia reticulata. Within a few years these fishes evolved an increased asymptotic size and size and age at maturity in response to reduced predation. Roa \& Quiñones (1998) have taken this point further, by arguing from a theoretical analysis of empirical results by Banse \& Mosher (1980) that the ratio $C L_{50,1} / C L_{\infty}$ is constant across the animal kingdom, with the exception of small metazoans. The results of this work corroborate Roa \& Quiñones's finding. The value of the proposed constant $C L_{50 \%} / C L_{\infty}$ ratio for female squat lobsters locates the size at $50 \%$ maturity at about $60 \%$ of the asymptotic size. This constant needs to be evaluated for other species before our results can be generalised.

Acknowledgements. Three anonymous reviewers made several comments and criticisms that greatly improved the first version of the manuscript. The work was funded by FONDECYT grant 1950090 to R.R. and by a CONICYT graduate scholarship to F.T

\section{LITERATURE CITED}

Anonymous (1995) FORTRAN for PowerStation programmer's guide. Microsoft Corp Redmond, WA

Anonymous (1996) Chilean oceanographic maps. Hydrographic and Oceanographic Service of the Chilean Navy, Valparaíso (in Spanish)

Arancibia H, Meléndez R (1987) Alimentación de peces concurrentes en la pesquería de Pleuroncodes monodon Milne Edwards. Inv Pesq (Chile) 34:113-128

Bahamonde N, Henríquez G, Zuleta A, Bustos $\mathrm{H}$, Bahamonde R (1986) Population dynamics of squat lobsters, Family Galatheidae, in Chile. Can Spec Publ Fish Aquat Sci 92: $245-268$

Banse K, Mosher S (1980) Adult body mass and annual production/biomass relationships of field populations. Ecol Monogr 50:355-379

Bertness MD, Gaines SD, Bermudez D, Sanford E (1991) Extreme spatial variation in the growth and reproductive output of the acorn barnacle Semibalanus balanoides. Mar Ecol Prog Ser 75:91-100

Beyers CJdeB, Goosen PC (1987) Variations in fecundity and size at sexual maturity of female rock lobster Jasus lalandii in the Benguela ecosystem. S Afr J Mar Sci 5:513-521

Calow P, Townsend CR (1981) Resource utilization in growth. In: Townsend CR, Calow P (eds) Physiological ecology: an evolutionary approach to resource use. Blackwell Scientific Publications, Oxford, p 220-244

Campbell A, Eagles MD (1983) Size at maturity and fecundity of rock crabs, Cancer irroratus, from the Bay of Fundy and southwestern Nova Scotia. Fish Bull 81:357-362

Chen Y, Jackson DA, Harvey HH (1992) A comparison of von Bertalanffy and polynomial functions in modelling fish growth data. Can J Fish Aquat Sci 49:1228-1235

Crowley PH (1992) Resampling methods for computationintensive data analysis in ecology and evolution. Annu Rev Ecol Syst 23:405-447

Dugan JE, Wenner AM, Hubbard DM (1991) Geographic variation in the reproductive biology of the sand crab Emerita analoga (Stimpson) on the California coast. J Exp Mar Biol Ecol 150:63-81

Dunning JB, Danielson BJ, Pulliam HR (1992) Ecological processes that affect populations in complex landscapes. Oikos 65:169-175

Efron B, Tibshirani RJ (1993) An introduction to the bootstrap. Chapman \& Hall, New York

Fonseca TR (1989) An overview of the poleward undercurrent and upwelling along the Chilean coast. In: Neshyba SJ, Mooers CNK, Smith RL, Barber RT (eds) Poleward flows along eastern ocean boundaries. Coastal and estuarine studies. Springer-Verlag, New York, p 177-228

Gallardo VA (1980) Ecological relationships of benthic and bentho-demersal communities of the continental shelf off central Chile. Technical report, University of Concepción, Undersecretariat of Fishing, Concepción (in Spanish)

Gallardo VA, Cañete JI, Roa R, Enríquez-Briones S, Baltazar $M$ (1994) Recruitment of the squat lobster Pleuroncodes monodon on the continental shelf off central Chile. J Crust Biol 14: 665-669

Gallardo VA, Roa R, Carraso FD, Cañete JI, Enríquez-Briones $S$, Baltazar M (1996) Bathymetric and seasonal patterns in the sublittoral megafauna off central Chile. J Mar Biol Assoc UK 76:311-326

Hincs AH (1989) Geographic variation in size at maturity in brachyuran crabs. Bull Mar Sci 45:356-368

Hosmer DW, Lemeshow S (1989) Applied logistic regression. John Wiley and Sons, New York 
Macdonald PDM, Pitcher TJ (1979) Age groups from size-frequency data: a versatile and efficient method of analyzing distribution mixtures. J Fish Res Bd Can 36:987-1001

Manly BFJ (1997) Randomization, bootstrap and Monte Carlo methods in biology. Chapman \& Hall, New York

Reznick DN, Shaw FH, Rodd FH, Shaw RG (1997) Evaluation of the rate of evolution in natural populations of guppies (Poecilia reticulata). Science 275:1934-1937

Roa R (1993) Annual growth and maturity function of the squat lobster Pleuroncodes monodon in central Chile. Mar Ecol Prog Ser 97:157-166

Roa R, Ernst B (1996) Age structure, annual growth, and variance of size-at-age of the shrimp Heterocarous reedi. Mar Ecol Prog Ser 137:59-70

Roa R, Gallardo VA, Ernst B, Baltazar M, Cañete JI, EnríquezBriones S (1995) Nursery ground, age structure and abundance of juvenile squat lobster Pleuroncodes monodon on

Editorial responsibility: Otto Kinne (Editor)

Oldendorf/Luhe, Germany the continental shelf off central Chile. Mar Ecol Prog Ser $116: 47-54$

Roa R, Quiñones R (1998) Theoretical analysis of the relationship between production per unit biomass and animal body size. Oikos 81:161-167

Somerton DA (1981.) Regional variation in the size of maturity of two species of tanner crab (Chionoecetes bairdi and $C$. opilio) in the eastern Bering Sea, and its use in defining management subareas. Can J Fish Aquat Sci 38:163-174

Somerton DA, Otto RS (1986) Distribution and reproductive biology of the golden king crab, Lithodes aequispina, in the eastern Bering Sea. Fish Bull 84:571-584

Wenner AM, Page HM, Siegel PR (1985) Variation in size at onset of egg production. In: Wenner AM (ed) Crustacean issues 3. Balkema, Rotterdam, p 149-164

Wilkinson L (1988) SYSTAT: the system for statistics. SYSTAT Inc, Evanston, IL

Submitted: April 30, 1997; Accepted: March 30, 1998

Proofs received from author(s): June 3,1998 